\title{
The highlights in the $3^{\text {rd }}$ International Uniportal VATS Course
}

\author{
Skylar Gao \\ Editorial Office of Journal of Visualized Surgery, Guangzhou 510220, China \\ Correspondence to: Skylar Gao. Science Editor, Editorial Office, Journal of Visualized Surgery, AME Publishing Company, Room 807, Jinhui Building, \\ No. 123, Jiefang Road, Yuexiu District, Guangzhou 510000, China. Email: jovs@amepc.org.
}

Received: 24 March 2016; Accepted: 04 April 2016; Published: 27 April 2016.

doi: 10.21037 /jovs.2016.04.06

View this article at: http://dx.doi.org/10.21037/jovs.2016.04.06

The $3^{\text {rd }}$ International Uniportal VATS Course jointly organized by the University Hospital Charité in Berlin, Germany (Prof. Mahmoud Ismail: course director) (Figure 1), the University Hospital in Coruña, Spain and the Shanghai Pulmonary Hospital, Tongji University Shanghai, China (Prof. Diego Gonzalez-Rivas: course director) (Figure 2), was held successfully in Campus Charité Mitte (CCM), Berlin, Germany from March $16^{\text {th }}$ to $18^{\text {th }}, 2016$.

The University Hospital Charité in Berlin (CharitéUniversitätsmedizin Berlin) is one of the largest teaching hospitals in Europe, affiliated with both Humboldt University and Freie Universität Berlin. With numerous Collaborative Research Centers (CRC) of the Deutsche Forschungsgemeinschaft, Charité is one of Germany's most research-intensive medical institutions. From 2012 to 2014, Charite has been ranked by Focus as the best of over 1,000 hospitals in Germany.

Grandly held in one of the four campuses of the Charite, the CCM (Figure 3), the $3^{\text {rd }}$ International Uniportal VATS Course has gathered numerous famous thoracic surgeons, together working on the better development of uniportal VATS. The course contained three parts-lectures on different aspects of uniportal VATS in the first day, live surgery in the second day and Wetlab in the third day. Let's review the highlights of the $3^{\text {rd }}$ International Uniportal VATS Course!

\section{Day 1 cutting-edge sharing, exploring the world of uniportal VATS}

On the first day, the focus lied on the lecture sharing. Tremendous speeches on research instructions in thoracic surgery, different approaches in uniportal VATS, tips and tricks of operative technique in uniprotal VATS, advanced cases, future vision of uniportal VATS and so on were

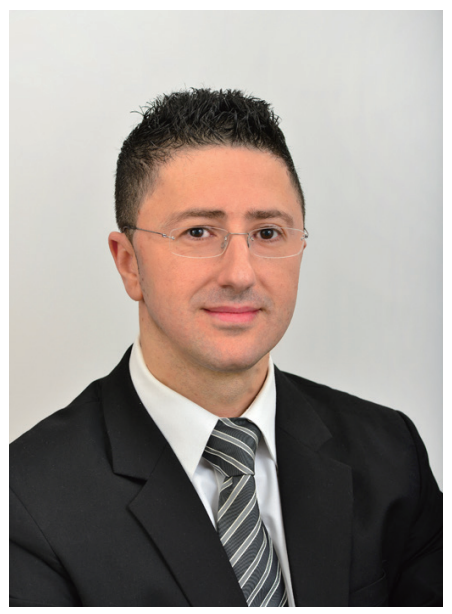

Figure 1 Prof. Mahmoud Ismail.

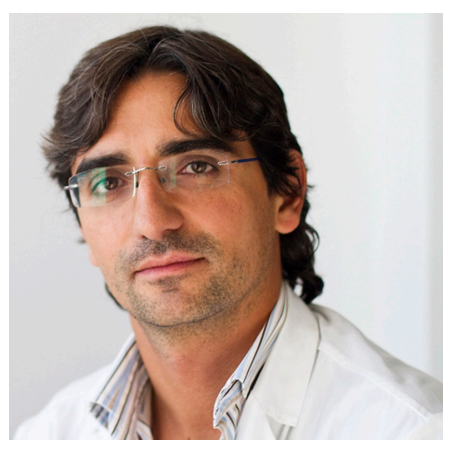

Figure 2 Prof. Diego Gonzalez-Rivas.

impressively shared by world-known thoracic surgeons all around the world (Figures 4-6). About 130 participants from different countries in the world were attending the course (Figure 7).

Another striking news for this course is that many 
excellent Chinese experts on uniprotal VATS were as well invited to share the Chinese VATS experience, a big move for the communication between Chinese surgeons and European surgeons in the thoracic world (Figure 8).

As a tossed stone raises thousands of ripples, so did the sharing. Activated by the inspirational lectures, audience put forward one after another questions, inspiring quite a lot sparkles (Figures 9,10). Simply as it may be, the interaction is a significant step to the future of uniportal VATS.

After the whole day's lectures came the delicious dinner. While tasting the nice food, experts still seized the precious opportunity of gathering together to chat about everything, or continue the day's discussion. For them, every second of

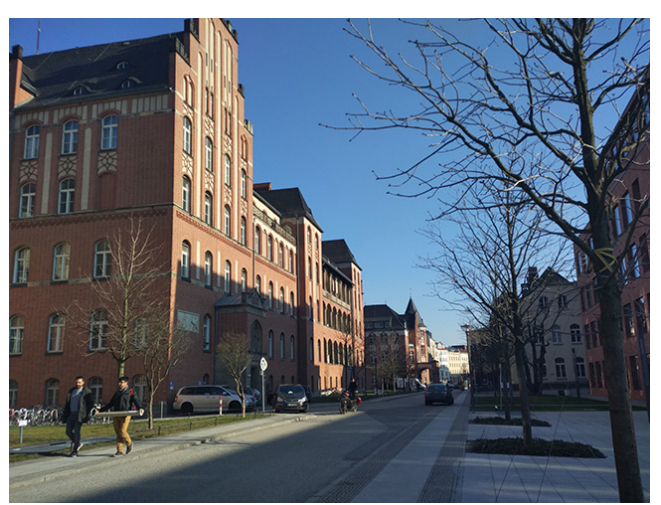

Figure 3 A glance on the Campus Charité Mitte (CCM). gathering means a lot (Figure 11).

\section{Day 2 live surgery from China and Europe}

Farewell to the first day's lectures now came the visual feast-live surgery presentation! Not only showed the skillful surgeries from the Charité, the course also presented the live broadcasting from the Shanghai Pulmonary Hospital. One surgery performed and presented by two countries, isn't that a spectacle moment? No wonder active discussion was non-stopping (Figures 12,13).

Other than the live surgery, VATS simulation equipment was also provided outside the meeting room (Figure 14).

\section{Day 3 let's join the Wetlab}

Time for the hands-on class-Wetlab moment! This time, the Wetlab course was separated in several groups, together doing left upper and lower lobectomy, left lower lobectomy, right upper and lower lobectomy and right lower lobectomy and segmentectomy through the animal model. Though the Wetlab only last for one day, every participant learned a lot from the practices (Figures 15-17).

\section{Jovs in the Course}

To fit with the theme of this course, we brought two
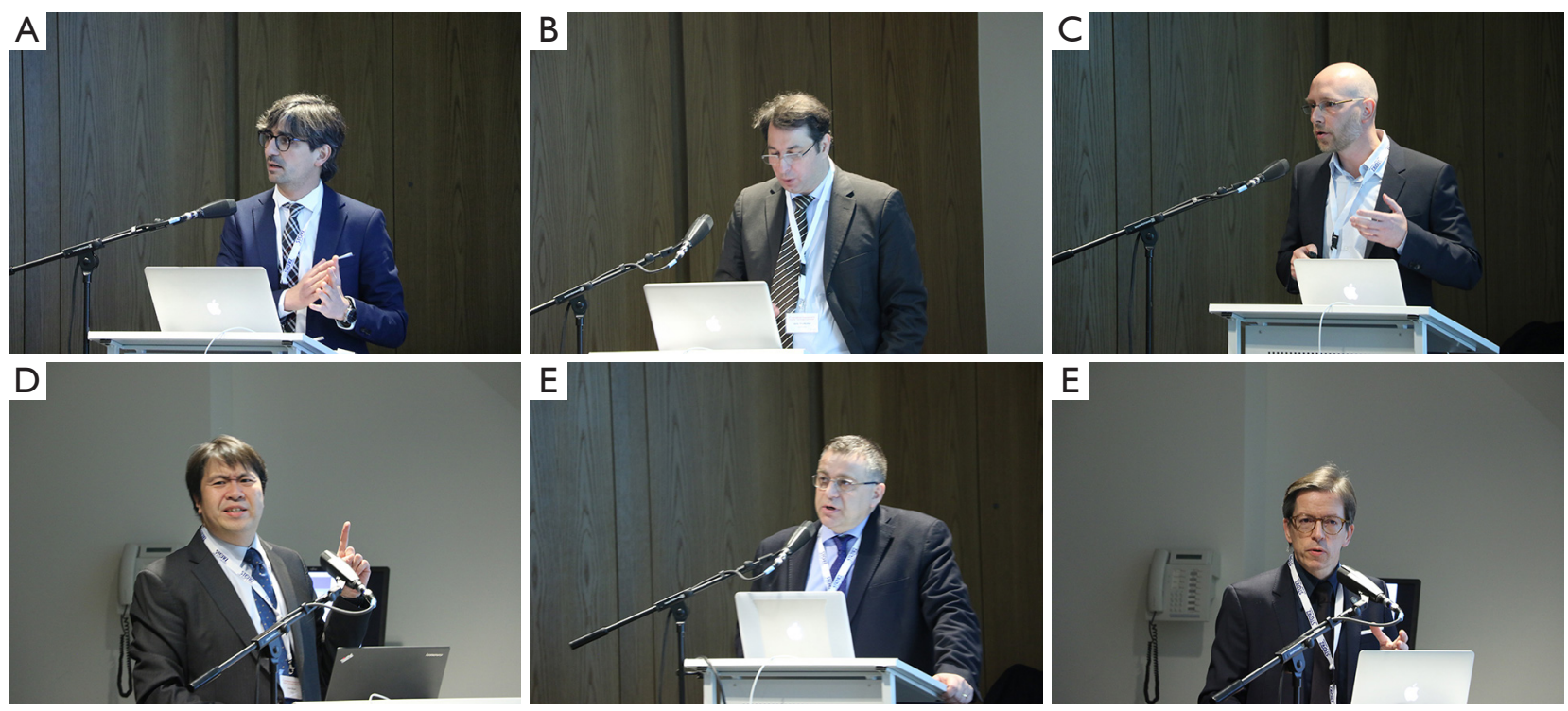

Figure 4 Lecture sharing part 1. (A) Prof. Diego Gonzalez-Rivas; (B) Prof. Jens Neudecker; (C) Prof. Andreas Hocke; (D) Prof. Alan Sihoe; (E) Prof. Gaetano Rocco; (F) Prof. Jens C. Rücker. 

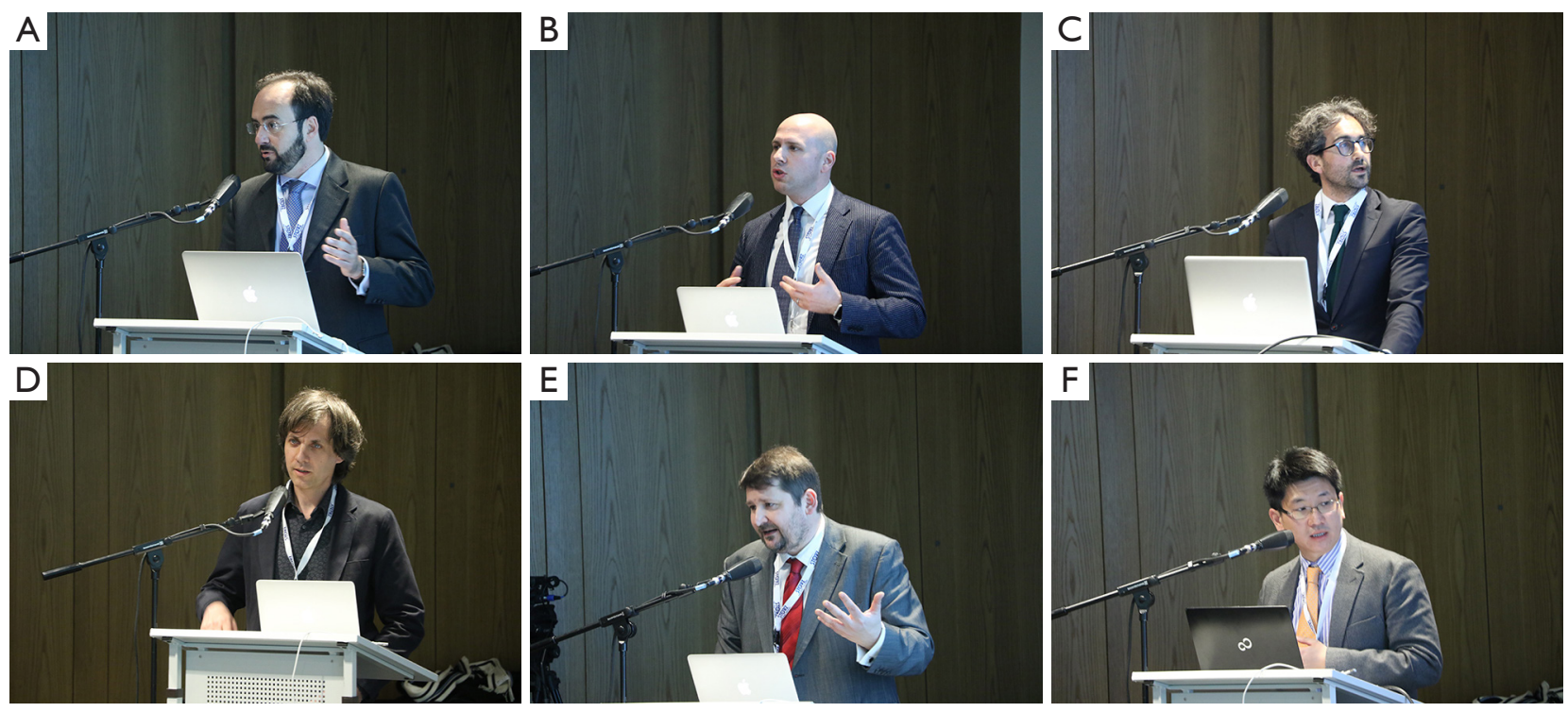

Figure 5 Lecture sharing part 2. (A) Prof. Javier Gallego; (B) Prof. Marco Scarci; (C) Prof. Ricardo Fernandez; (D) Prof. Tomaz Stupnik; (E) Prof. Antonio Martin-Ucar; (F) Prof. Calvin Ng.
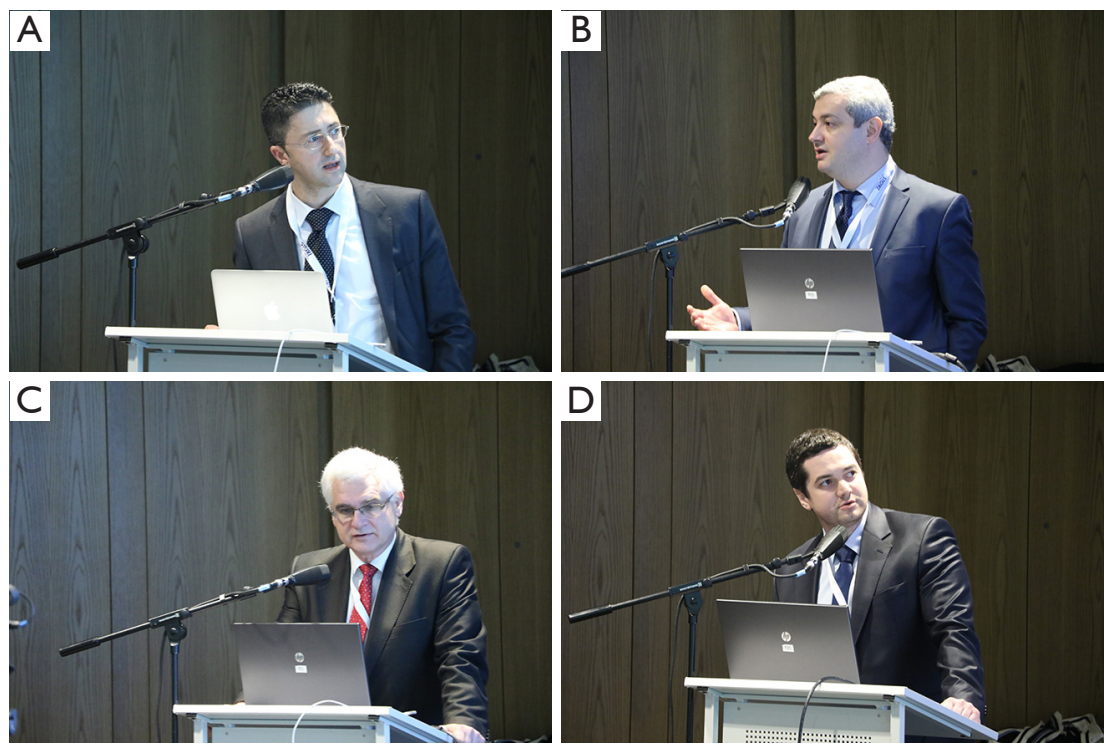

Figure 6 Lecture sharing part 3. (A) Prof. Mahmoud Ismail; (B) Prof. Vadim Pischik; (C) Prof Marcin Zielinski; (D) Prof. Dmitrii Sekhniaidze. 


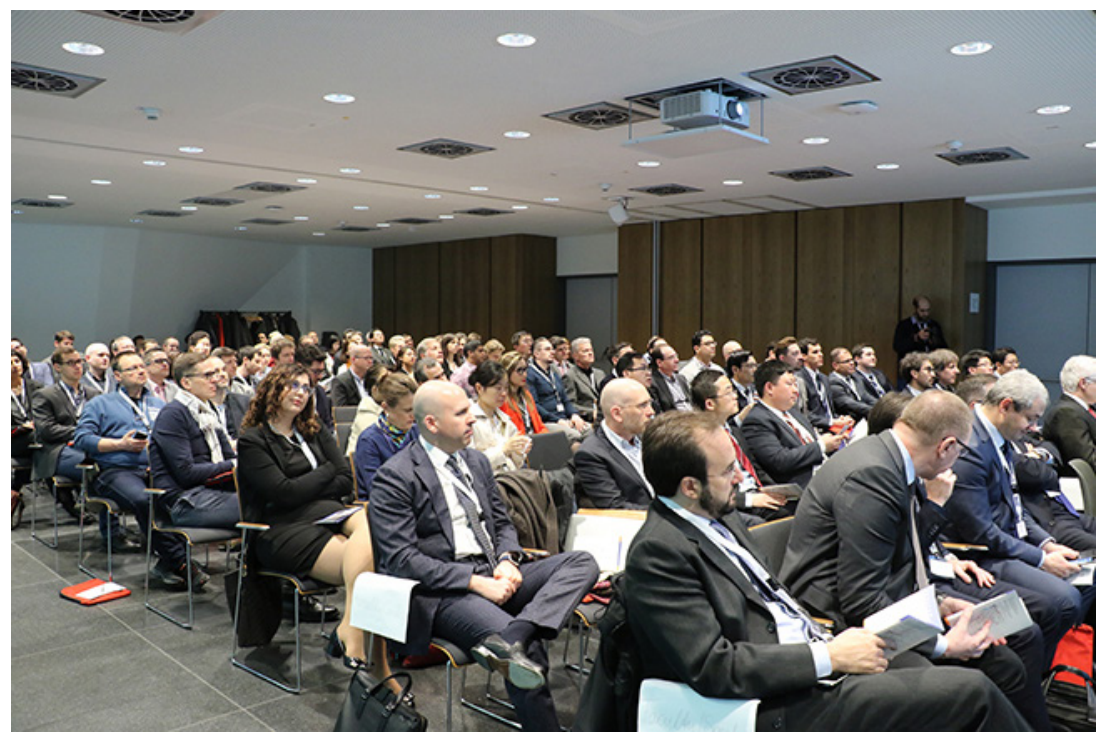

Figure 7 Fully occupied meeting room, about 130 participants from the whole world.
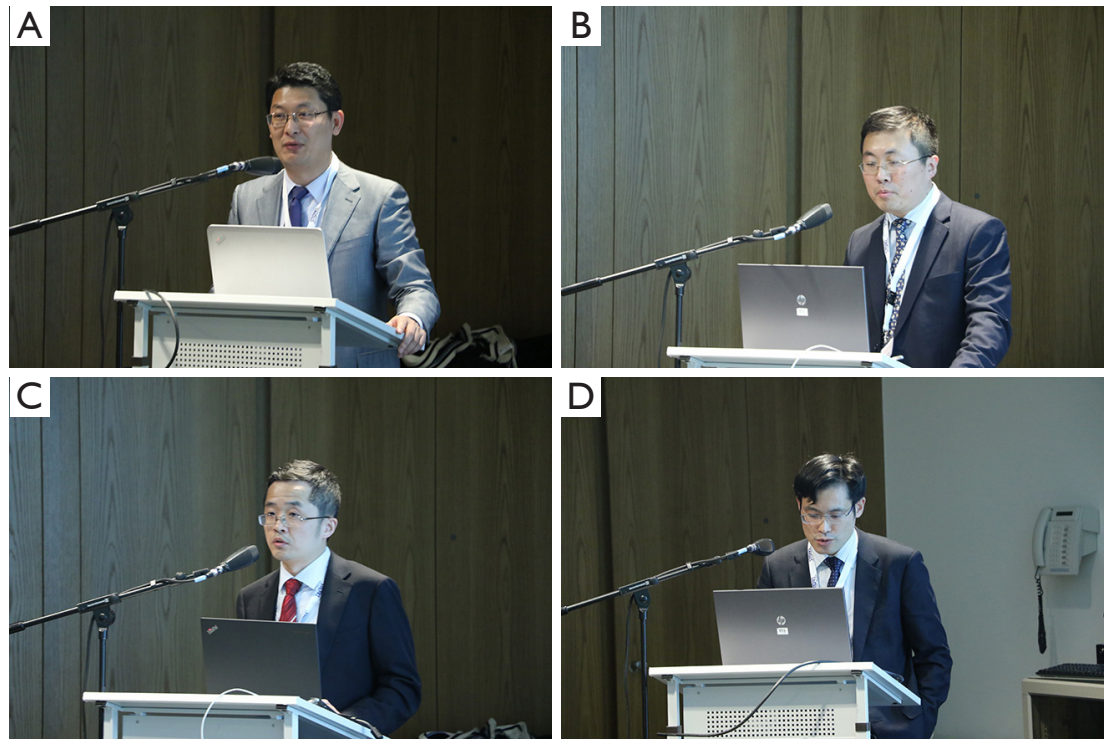

Figure 8 Chinese surgeons in the course. (A) Prof. Guangsuo Wang; (B) Prof. Deping Zhao; (C) Prof. Haifeng Wang; (D) Prof. Hecheng Li.

masterpieces of thoracic surgery-Uniportal Video-assisted Thoracic Surgery and Video-assisted Thoracic Surgery edited by Prof. Diego Gonzalez-Rivas, Gaetano Rocco, Alan Sihoe and other experts, attracting plentiful attention (Figure 18).

Except good news from the masterpieces, we were also more than delighted to talk to our old friends and as well to meet new friends (Figures 19-22).

The $3^{\text {rd }}$ International Uniportal VATS Course finally ended in every expert' satisfaction. Want to know more the comments on this course? Let's click on the following video (Figure 23)!

\section{Acknowledgements}

None. 

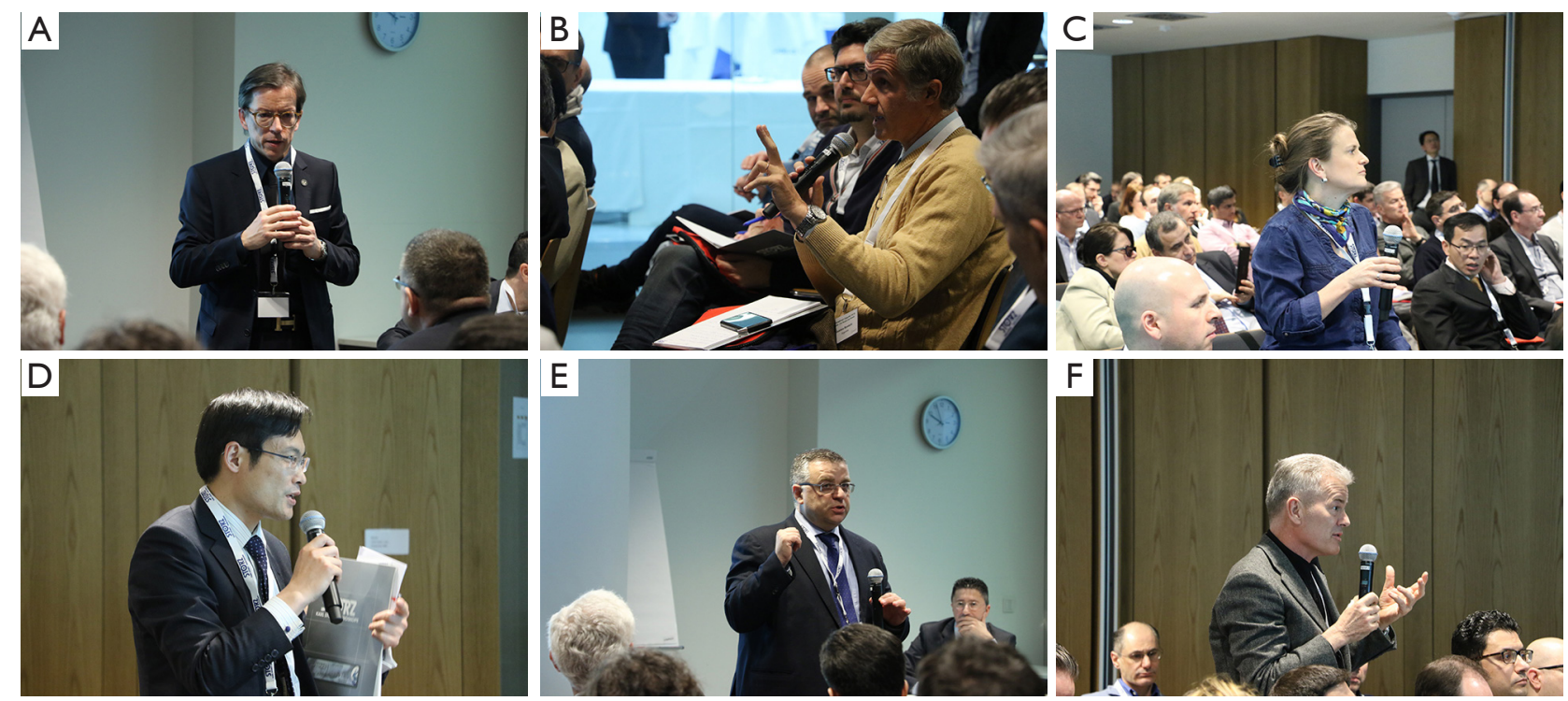

Figure 9 Active discussion.
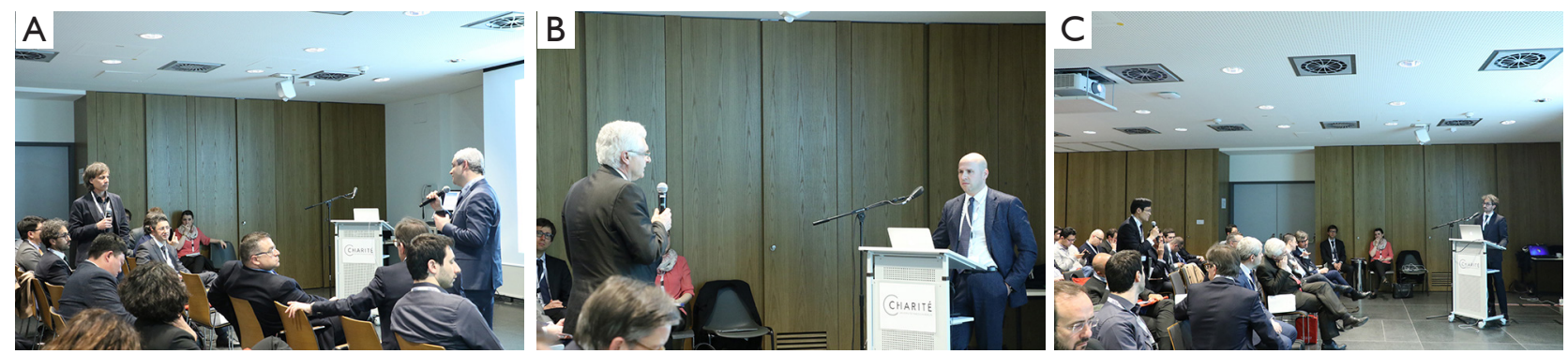

Figure 10 Face to face. (A) Prof. Tomaz Stupnik vs. Prof. Vadim Pischik; (B) Prof. Marcin Zielinski vs. Prof. Marco Scarci; (C) Prof. Hecheng Li vs. Prof. Ricardo Fernandez.
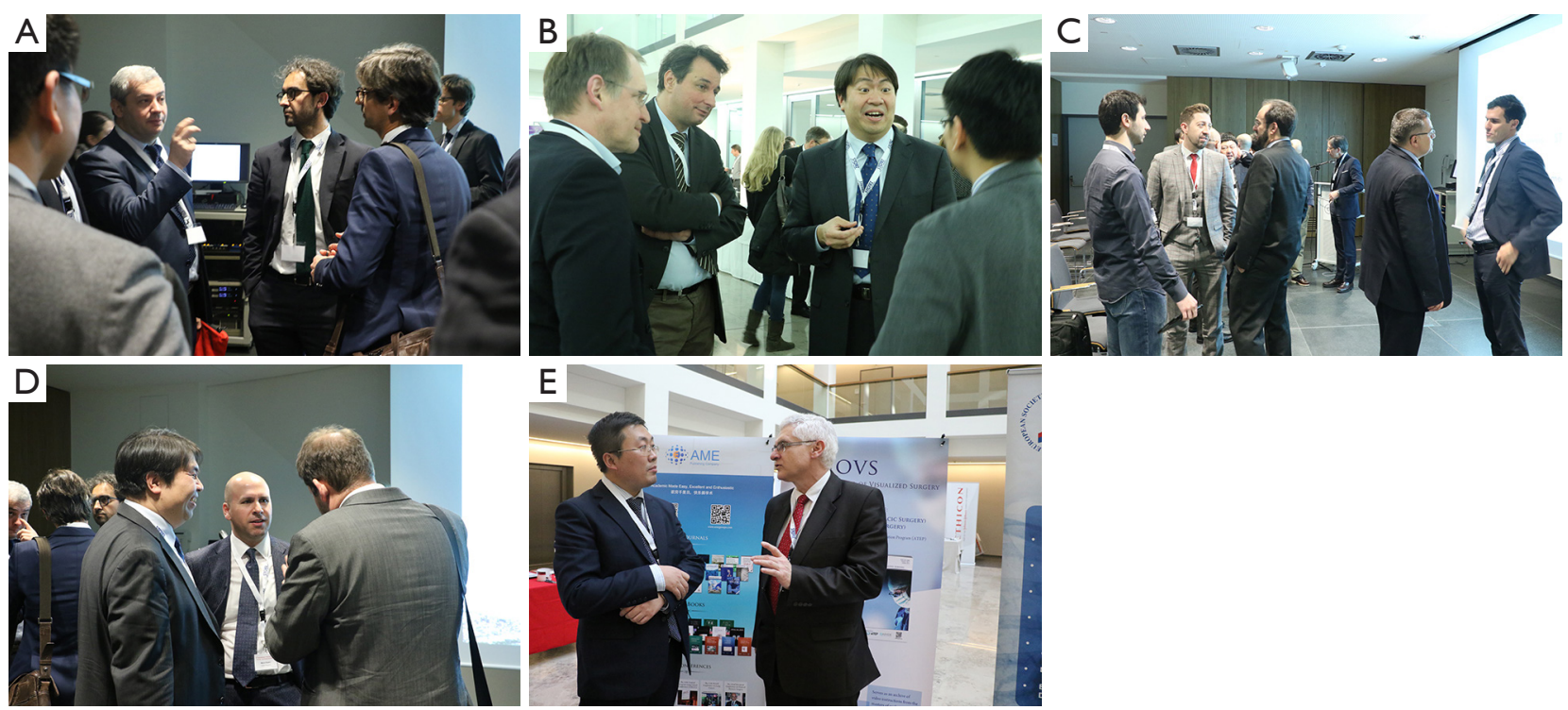

Figure 11 Chatting after the day. 

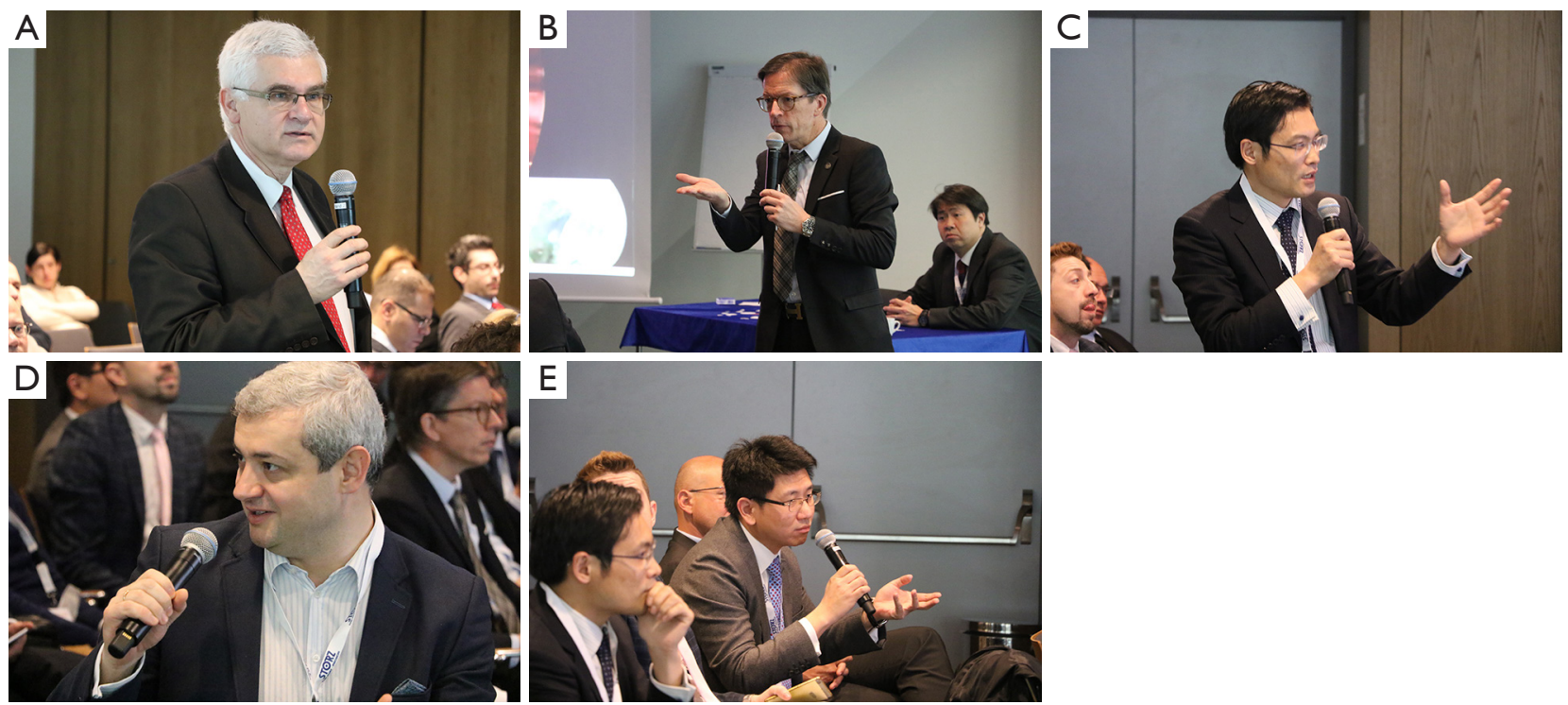

Figure 12 Discussion in the live surgery part 1.
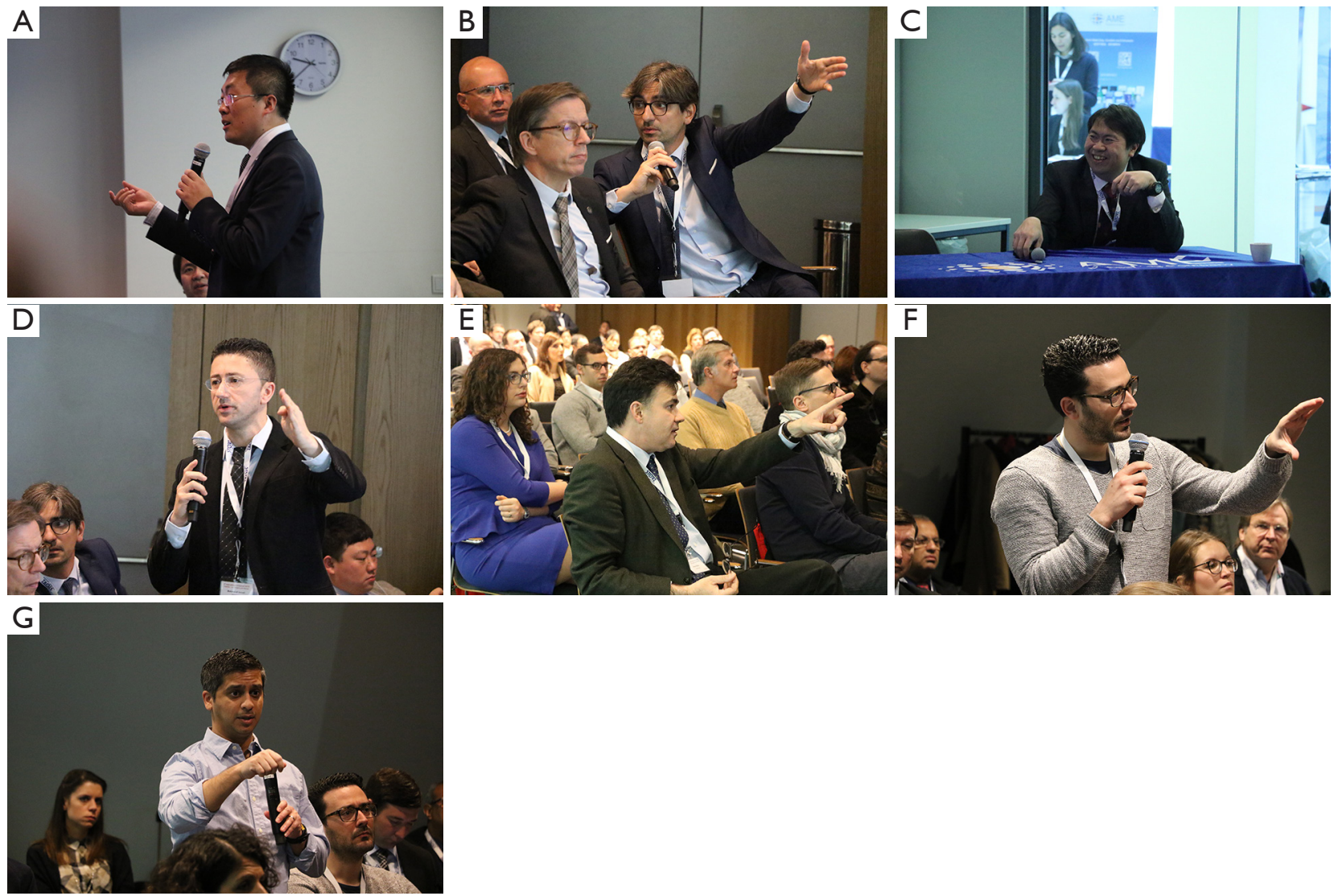

Figure 13 Discussion in the live surgery part 2. 


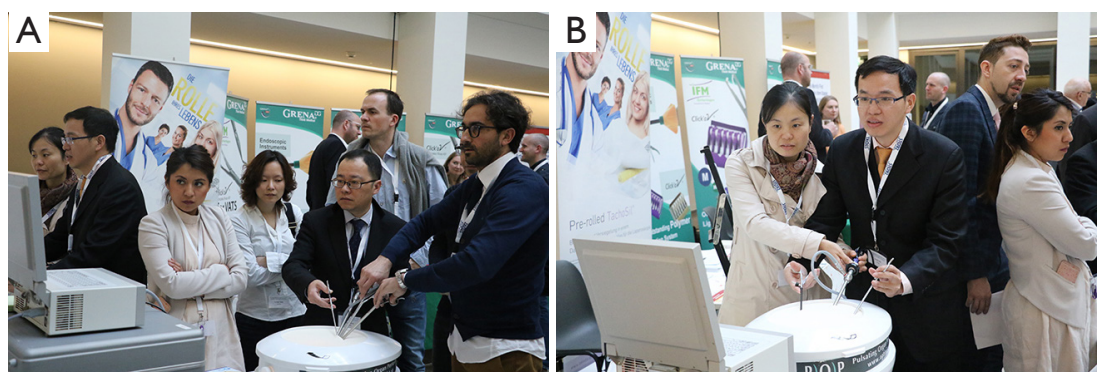

Figure 14 VATS simulation practice.

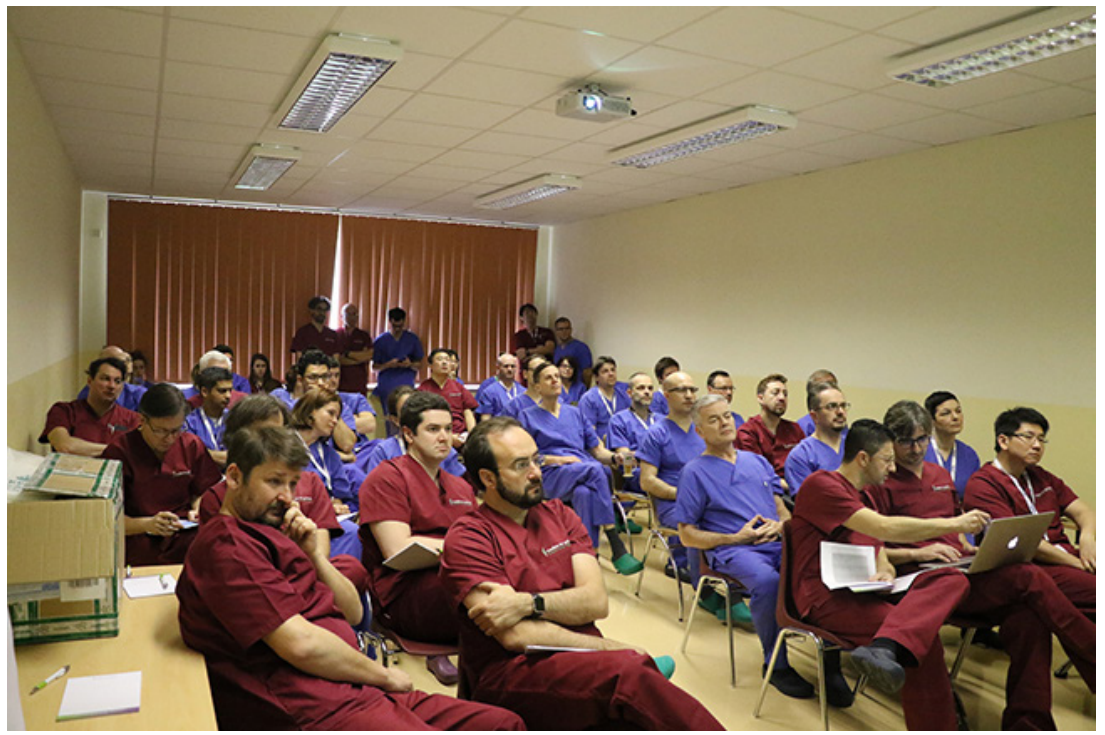

Figure 15 Before the Wetlab.
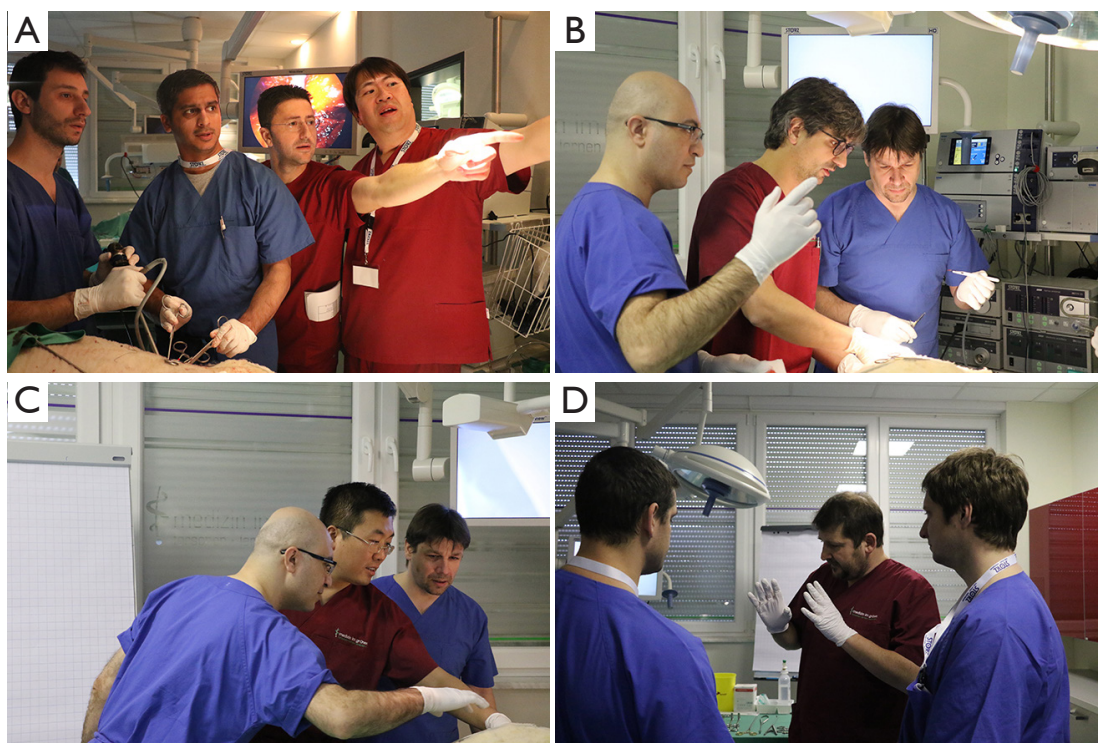

Figure 16 In the Wetlab. 

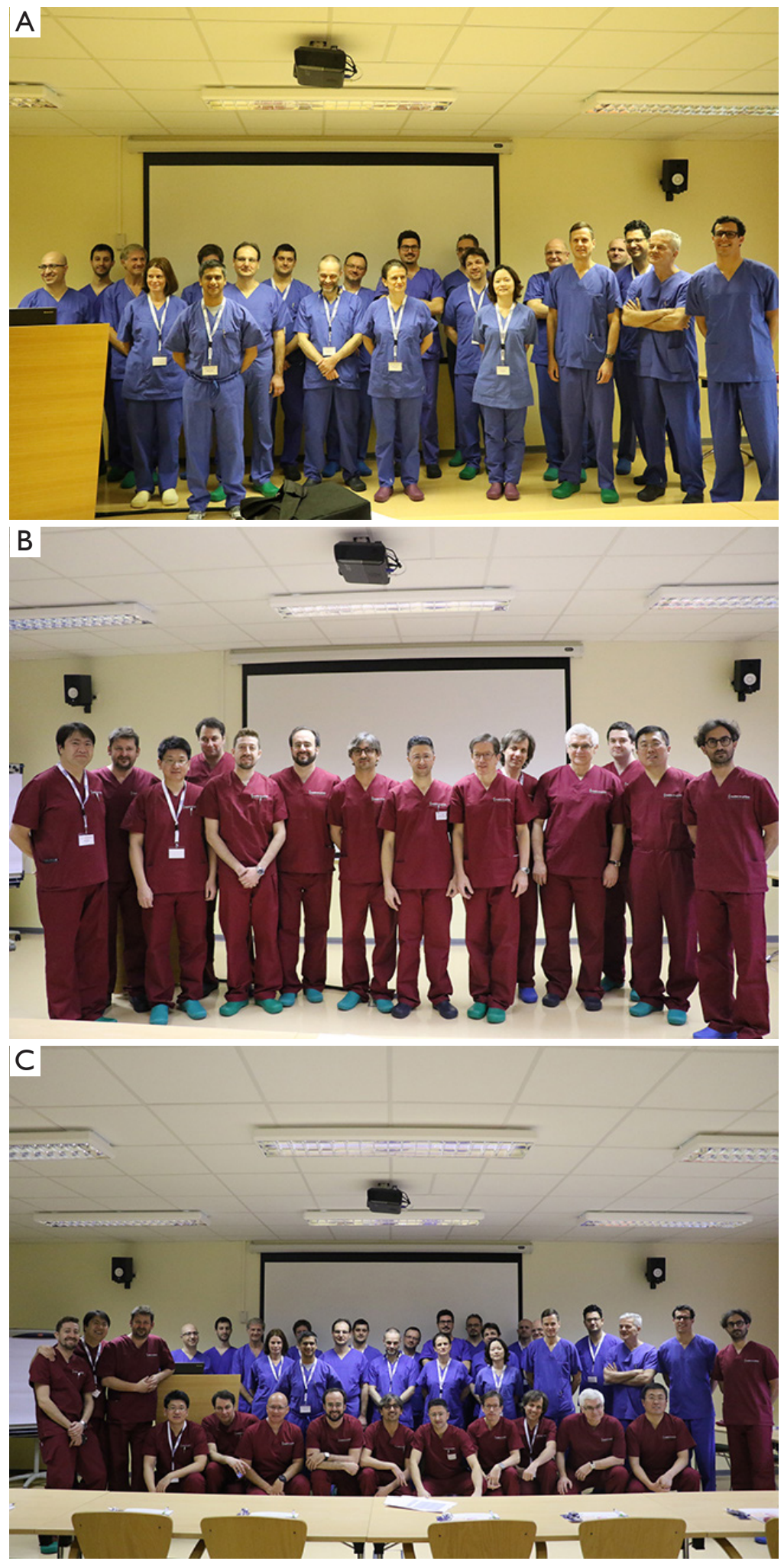

Figure 17 Wetlab group. 

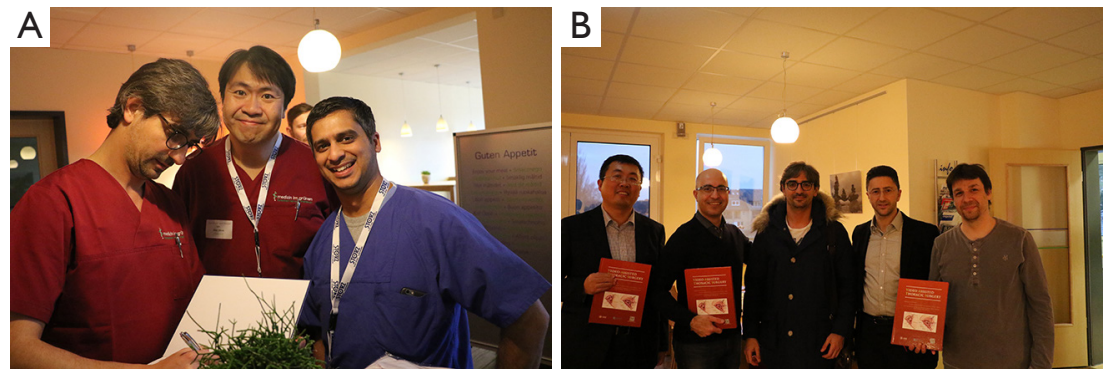

Figure 18 Presenting the books. (A) Prof. Diego Gonzalez-Rivas and Prof. Alan Sihoe presented Uniportal Video-assisted Thoracic Surgery to Dr. Alykhan Nagi; (B) Prof. Diego Gonzalez-Rivas and Prof. Mahmoud Ismail presented Video-assisted Thoracic Surgery to Dr. Deping Zhao, Dr. Hamid Mahoozi and Dr. Ermim as a prize for the best wetlab team.
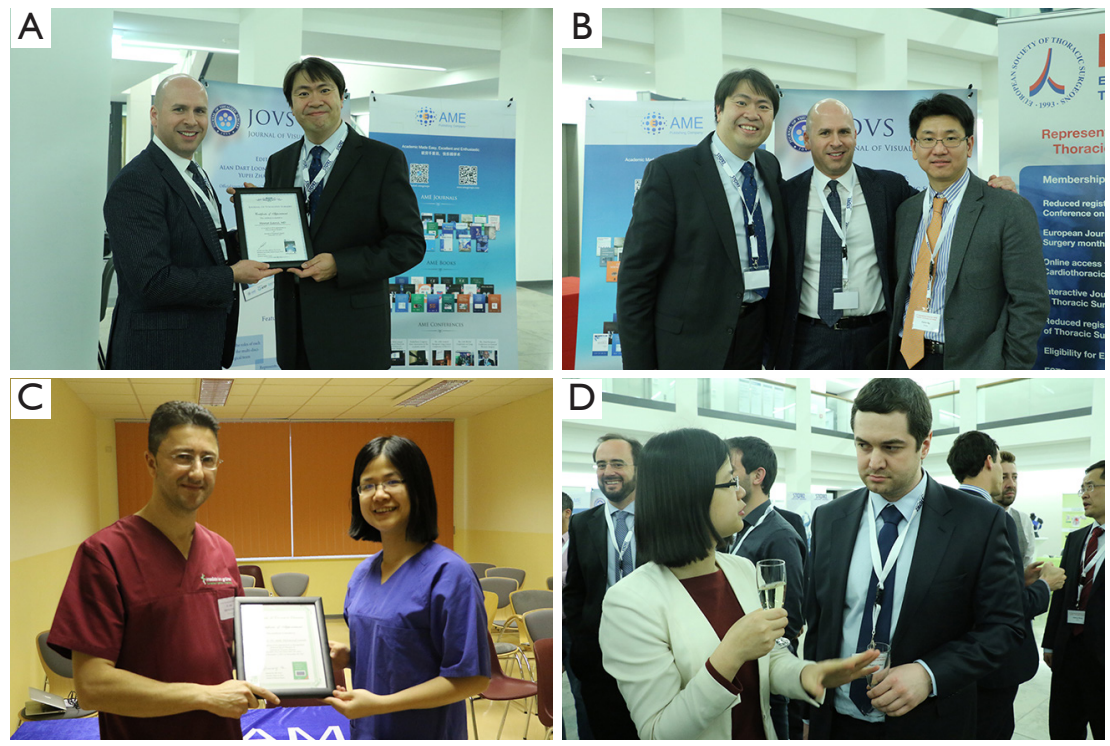

Figure 19 Meeting professor part 1. (A) Prof. Alan Sihoe, Editor-in-chief of FOVS, presented Editorial Board certificate to $70 V S$ Editorial Board members, Prof. Marco Scarci; (B) photo of Prof. Alan Sihoe, Prof. Marco Scarci and Prof. Clavin Ng; (C) AME editor Miss Grace presented Editorial Board certificate to FTD Editorial Board members, Prof. Mahmoud Ismail, course director; (D) AME editor Miss Grace talked with Prof. Dmitrii Sekhniaidze, author of $7 T D$ special issue.

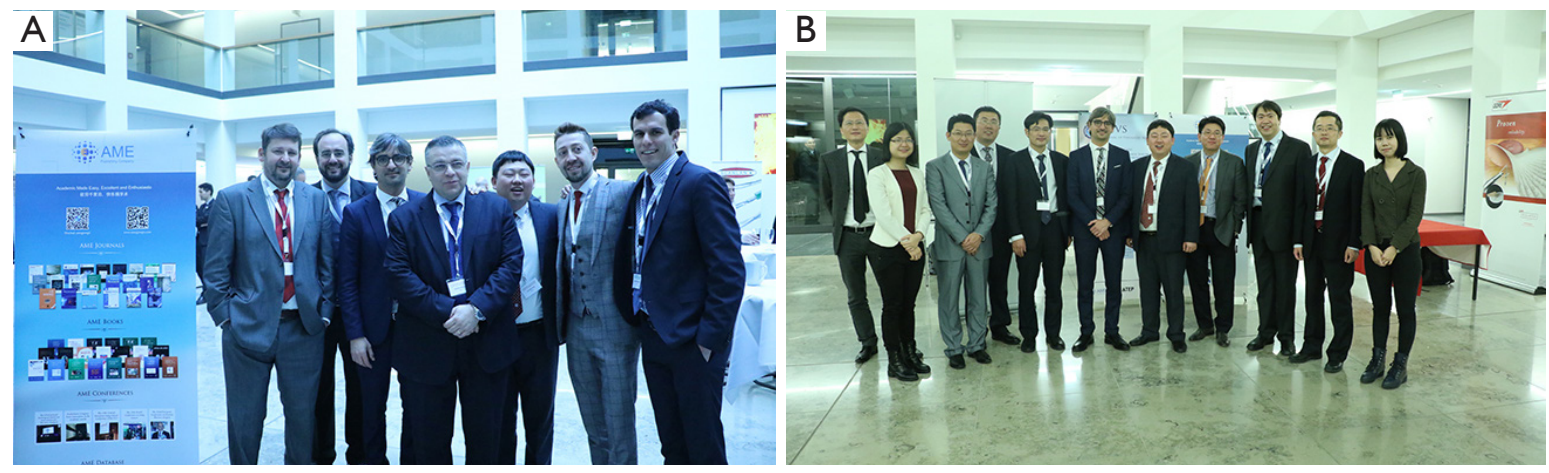

Figure 20 Meet the professor part 2. (A) From left to right: Prof. Antonio Martin-Ucar, Prof. Javier Gallego, Prof. Diego Gonzalez-Rivas, Prof. Gaetano Rocco, Prof. Tim Young, Prof. Luis Hernandez, Prof. Miguel Mesa Guzman; (B) from left to right: Mr. Weijian Yang, Miss Grace Li, Prof. Guangsuo Wang, Prof. Deping Zhao, Prof. Hecheng Li, Prof. Diego Gonzalez-Rivas, Prof. Tim Young, Prof. Clavin Ng, Prof. Alan Sihoe, Prof. Haifeng Wang, Miss Skylar Gao. 

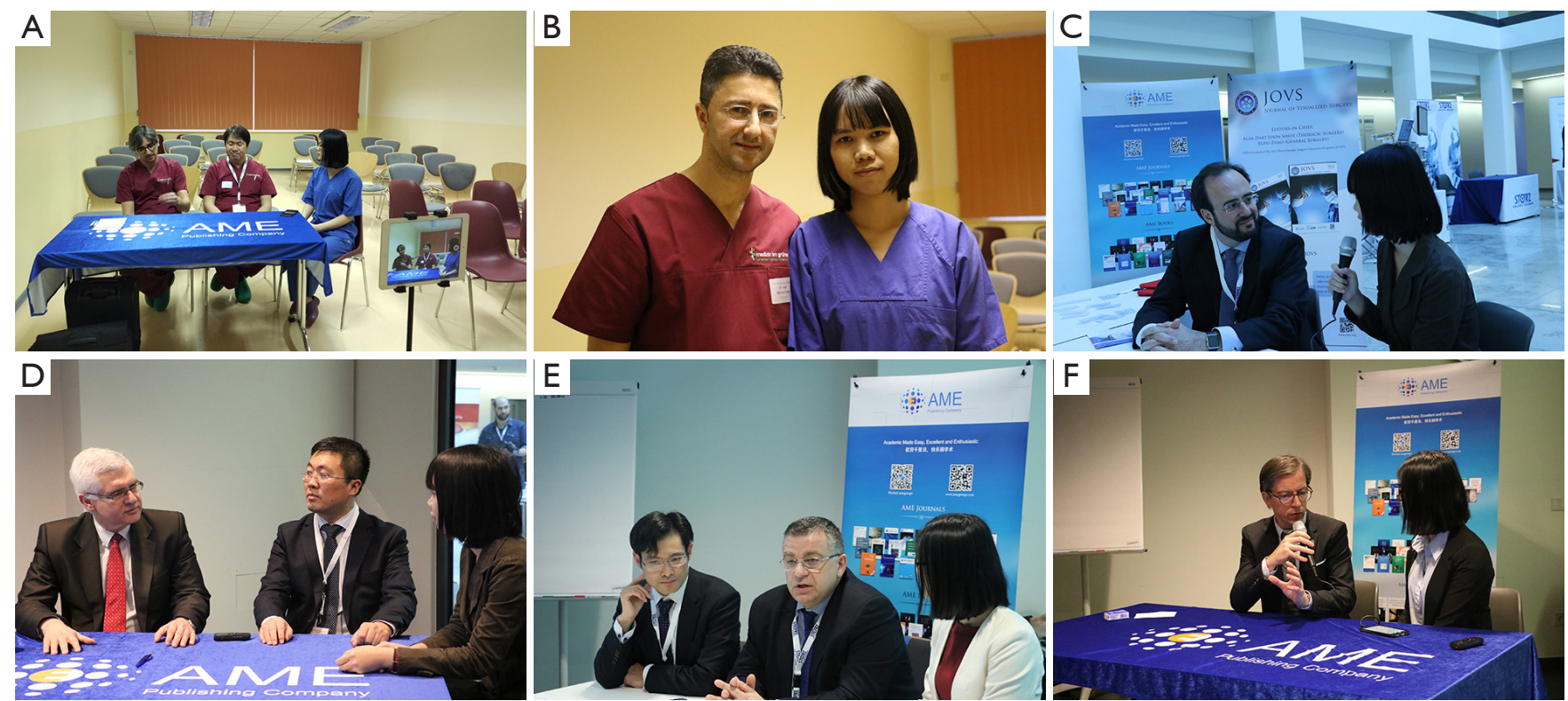

Figure 21 Meet the professor part 3. (A) Interview with Prof. Diego Gonzalez-Rivas and Prof. Alan Sihoe; (B) interview with Prof. Mahmoud Ismail; (C) interview with Prof. Javier Gallego; (D) interview with Prof. Marcin Zielinski and Prof. Deping Zhao; (E) interview with Prof. Hecheng Li and Prof. Gaetano Rocco; (F) interview with Prof. Jens C. Rücker.

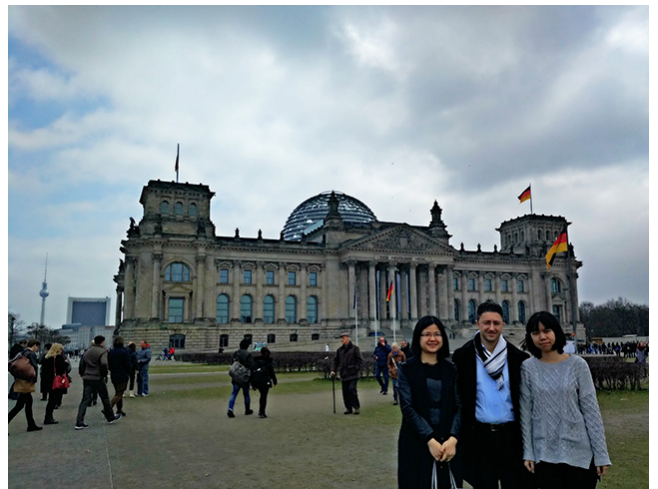

Figure 22 A photo with course director, Prof. Mahmoud Ismail at the Reichstag in Berlin.

\section{Footnote}

Conflicts of Interest: The author has no conflicts of interest to declare.

doi: 10.21037/jovs.2016.04.06

Cite this article as: Gao $\mathrm{S}$. The highlights in the $3^{\text {rd }}$ International Uniportal VATS Course. J Vis Surg 2016;2:88.

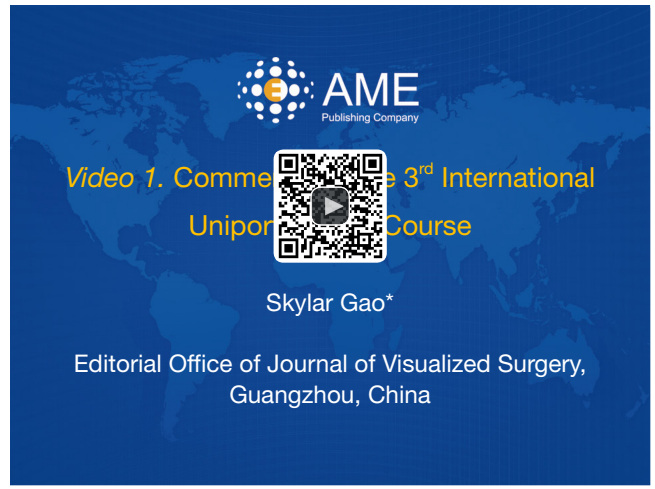

Figure 23 Comments on the $3^{\text {rd }}$ International Uniportal VATS Course (1). Available online: http://www.asvide.com/articles/961

\section{References}

1. Gao S. Comments on the $3^{\text {rd }}$ International Uniportal VATS Course. Asvide 2016;3:205. Available online: http:// www.asvide.com/articles/961 